\title{
A Study on Numerical Analysis of Smoke Protection Characteristic using Air Curtain in $2^{\text {nd }}$ Floor Building
}

\author{
Su-Gak Lee, Jung-Yup Kim, Seung-Won Jeon \\ Fire Research Institute/Korea Institute of Civil Engineering and Building Technology \\ 182gil-64, Baekgok-ri, Mado-myeon, Hwaseong-si, Gyeonggi-do, 445-861, Republic of Korea \\ wm8284@kict.re.kr; jykim1@kict.re.kr; seungwonjeon@kict.re.kr
}

\section{Extended Abstract}

Recently buildings tend to be taller and larger, they are more vulnerable to fire from a fire safety and firefighting capability point of view. In particular, such buildings with a large space could be a smoke spread route during the fire, so that it becomes more difficult to create a fire compartmentation which is one of the important smoke control design concept. Consequentially, it leads to difficulties in smoke control caused by temperature, external wind pressure, building structure and internal air flow.

When we consider the constant fire growth characteristics in fuel-dominant fire in a building with the large space that accommodates the large number of person, a lot of smokes are generated, so that suffocation due to smoke inhalation could lead to loss of lives. Therefore, it has been pointed out that proper smoke control system is needed to deal with the fire in a large space. The solutions that are able to deal with smoke control and isolation so far might include mechanical smoke eliminating, air supply \& exhaust control, air injection, whirlwind technology, fluid bag technology, smoke protection screen, air curtain, smoke temperature lowering technology and water screen technology. Among them, it has been noticed that air curtain technology has not been well studied.

Klaus and Horn [1] studied on prevention of the smoke spread from the large space to the surrounding space by use of air curtain, and the smoke isolation effect in channel structure depending on air injection speed was investigated by Stein [2]. Wilkinson [3] conducted the study on smoke spread prevention performance and major design factors for fire smoke rises along the stair, using scale model test and numerical analysis.

The performance of air curtain on smoke isolation is evaluated by adjusting the heat source. Smoke spread behavior and the performance of air curtain on prevention of smoke spread was investigated in the escalator structure between floors. ANSYS CFX [4] is chosen as solver which accuracy and feasibility have been proven and is used widely for flow analysis. The dimension of central plaza of the building was $10 \times 10 \times 2.5 \mathrm{~m}$, and the length, width and height of the corridor divided into 4 ways were $6 \times 2 \times 2.5 \mathrm{~m}$. The plaza and corridor on $2^{\text {nd }}$ floor has a same structure as the $1^{\text {st }}$ floor, where floors are linked with escalator.

Air curtain for smoke isolation, comprising of air supply nozzle (inlet) and exhaust hood (outlet), was equipped in front of escalator on $2^{\text {nd }}$ floor in order to analyze the smoke protection characteristics against the smoke from the $1^{\text {st }}$ floor. The width of air supply nozzle of air curtain, injection speed , the width of exhaust hood and exhaust speed are respectively $0.01 \mathrm{~m}, 30 \mathrm{~m} / \mathrm{s}$, $0.3 \mathrm{~m}$ and $1 \mathrm{~m} / \mathrm{s}$. Here, air supply and exhaust flow were set equally ( $\mathrm{Q}_{\mathrm{in}}=\mathrm{Q}_{\text {out }}$ ). The end of corridor except for the side to escalator was set as opening, initial indoor temperature was given as $20^{\circ} \mathrm{C}$. The fire source sized $1 \mathrm{x} 1 \mathrm{~m}$ was located at the center of the plaza on the $1^{\text {st }}$ floor and numerical analysis was performed with three caloric values of fire, 0.5, 1.0 and $1.5 \mathrm{MW}$. Computational domain comprises of 8,100,000 hexa-grids as lattice structure. Denser lattice was generated near the air curtain due to severe flow change.

Results show smoke behavior with different three condition depending caloric value, 0.5, 1.0 and 1.5 MW. Smoke spread was completely isolated by air curtain and the temperature at the center and corridor on the $2^{\text {nd }}$ floor remained the same as given initial condition in case of caloric value of $0.5 \mathrm{MW}$, whereas small amount of smoke were penetrated under the air curtain and spread uniformly all over the $2^{\text {nd }}$ floor, the smoke was gathered on ceiling in case of $1.0 \mathrm{MW}$. In case of $1.5 \mathrm{MW}$, more smoke was gathered on ceiling of escalator, resulting in penetration of considerable amount of smoke over the air curtain. Also it was observed that the part of smoke was uniformly spread over the $2^{\text {nd }}$ floor.

Simulation results also shows an ascending air current in connection of floors. Air current reflected from air curtain travels down to exhaust hood at a right angle in case of $0.5 \mathrm{MW}$, while air current reflected from air curtain is inclined toward a hall in 
$2^{\text {nd }}$ floor in case of 1.0 and 1.5 MW. Later results in constant entrainment of certain amount of smoke to $2^{\text {nd }}$ floor.

\section{Acknowledgements}

This work was supported by the National Research Council of Science \& Technology (NST) grant by the Korea government (MSIP) (No. CRC-16-02-KICT)

\section{References}

[1] W. K. Chow, "Smoke control by air curtain for spaces adjacent to atria," Journal of Environmental Systems, vol. 27, pp. 151-162, 1999.

[2] L. H. Hu, et al, "Confinement of fire-induced smoke and carbon monoxide transportation by air curtain in channel," Journal of Hazardous Materials, vol. 156, pp. 327-334, 2008.

[3] N. Luo, et al., "An experiment and simulation of smoke confinement utilizing an air curtain," Safety Science, vol. 59, pp. 10-18, 2013.

[4] ANSYS Inc., 2015, ANSYS CFX-Solver Theory Guide. 